\title{
Microstructure and properties of TP2 copper tube with La microalloying by horizontal continuous casting
}

\author{
Jin-hu Wu ${ }^{1,2}$, *Shi-hong Zhang ${ }^{1}$, Yan Chen ${ }^{1}$, Hai-hong Li ${ }^{3}$, Hong-wu Song ${ }^{1}$, Ming Cheng ${ }^{1}$, and Jin-song Liu ${ }^{1}$ \\ 1. Institute of Metal Research, Chinese Academy of Sciences, Shenyang 110016, China \\ 2. University of Chinese Academy of Sciences, Beijing 100049, China \\ 3. School of Environment and Materials Engineering, Yantai University, Yantai 264005, China
}

\begin{abstract}
The TP2 copper tube was prepared with La microalloying by horizontal continuous casting (HCC). The absorptivity of La and its effects on microstructure, tensile and corrosion properties of HCC TP2 copper tube were studied by means of the inductively coupled plasma optical emission spectrometer (ICP-OES), optical microscope $(\mathrm{OM})$, scanning electron microscope (SEM) and potentiodynamic polarization measurements. The results show that the absorptivity of La in the HCC TP2 copper tube is about $15 \%$ under antivacuum conditions due to the good chemical activities of La. The impurity elements in copper tube such as $\mathrm{O}, \mathrm{S}, \mathrm{Pb}$ and $\mathrm{Si}$ can be significantly reduced, and the average columnar dendrite spacing of the copper tube can also be reduced from $2.21 \mathrm{~mm}$ to $0.93 \mathrm{~mm}$ by adding La. The ultimate tensile strength and the elongation with and without La addition are almost unchanged. However, the annual corrosion rate of the HCC TP2 copper tube is reduced from $10.18 \mathrm{~mm} \cdot \mathrm{a}^{-1}$ to 9.37 $\mathrm{mm} \cdot \mathrm{a}^{-1}$ by the purification effect of trace La.
\end{abstract}

Key words: rare earth; microstructure; mechanical properties; corrosion resistance; HCC TP2 copper tube

CLC numbers: TP146.1 1

Document code: A

Article ID: 1672-6421(2018)01-031-06

$\mathrm{O}$ wing to the superior electrical and thermal conductivity, good mechanical properties and processability, as well as favorable corrosion resistance, pure copper, especially the phosphorus deoxidized copper (TP2), has been widely used for air-conditioning and refrigeration (ACR) tubes, electronic and electrical equipment, and energy and chemical industries ${ }^{[1-4]}$. With the requirements of energy saving and environmental protection, copper tubes with thinner walls and smaller diameter have been attracting more and more attention. Therefore, it is essential to improve the mechanical properties and corrosion resistance of copper tubes to meet the demand. Microalloying can be an effective method to improve the strength and corrosion resistance of copper tubes ${ }^{[5,6]}$.

Rare earth (RE) elements, known as the vitamins of industry, have been widely used as alloying additives to improve the properties of ferrous metals, aluminum alloys, magnesium alloys and copper alloys ${ }^{[7-10]}$.

\section{*Shi-hong Zhang}

Male, born in 1962, Professor, Ph.D. Research interests: advanced forming technology of sheet and tube, numerical simulation of forming process.

E-mail: shzhang@imr.ac.cn

Received: 2017-06-26; Accepted: 2017-11-15
Generally, there are two ways for RE elements to impose on copper and copper alloys: purification and alloying ${ }^{[11-15]}$. Zhang et al. found that RE element $\mathrm{Ce}$ can remove the $\mathrm{Fe}, \mathrm{Cl}, \mathrm{S}, \mathrm{P}$ and other impurities from pure copper, and when the Ce content reached $0.04 \%$, pure copper obtained fine microstructure and favorable comprehensive mechanical properties: the tensile strength, yield strength, and elongation after annealing were $251 \mathrm{MPa}, 116 \mathrm{MPa}$, and $37.22 \%$, respectively ${ }^{[16]}$. According to Ref. ${ }^{[17]}$, La had obvious effects on the solidification microstructure and the grain refinement of as-cast pure copper. With the increase of La content, the ultimate tensile strength, yield strength and microhardness increased gradually, but the elongation increased first and then decreased while La content exceeded 0.089 wt.\%. It suggested that the effects of grain refinement strengthening, solid solution strengthening, second phase strengthening and purifying by RE elements led to the improvement of mechanical properties. Except for pure copper, many studies focused on the effects of RE elements on copper alloys or composites ${ }^{[18-21]}$. For example, Mao et al. found that $\mathrm{RE}$ elements had an obvious effect on refining dendrite structure and grain size, as well as on purifying the melt of Cu-30Ni alloy. With the increase of RE content, 
the ultimate tensile strength, yield strength and elongation increased at first and then decreased after RE addition exceeded 0.095 wt. \%. The improvement of mechanical properties of $\mathrm{Cu}-$ 30Ni-0.095RE alloy was attributed to microstructure refining and matrix purifying by $\mathrm{RE}^{[22]}$. Wu et al. thought that RE could refine the as-cast microstructure and facilitate the precipitation of secondary Fe particles in the copper matrix by adding (0.050.30)wt.\% rare earth elements into $\mathrm{Cu}-6 \mathrm{wt} . \% \mathrm{Fe}$ composites ${ }^{[23]}$. Moreover, according to Ref. ${ }^{[24-26]}$, it was found that the galvanic corrosion was reduced, a dense corrosion product film was formed by the purification effect of rare earth, so the corrosion resistance of copper and copper alloys (i.e. imitation-gold copper alloy and Al-brass) with RE addition was improved significantly as compared with the initial alloy without RE addition.

According to the previous studies, adding small RE elements into copper and copper alloys would result in the improvement of the comprehensive properties of alloys. Most of the experiments were carried out under laboratory conditions or under vacuum conditions, however, the reports of RE applications in actual production processes are rather limited, especially in the studies applying RE in the HCC copper tube process. Therefore, in this paper, RE La was applied to the actual HCC copper tube process, and its effect on the microstructure, mechanical and corrosion properties of HCC TP2 copper tube was evaluated systematically.

\section{Experimental procedure}

Experiments were carried out in the horizontal continuous casting system for TP2 copper tube, which consisted of melting furnace, crystallizer and dragger. The electrolysis copper plate was melted in the main (or utility) frequency induction furnace. At $1,150{ }^{\circ} \mathrm{C}$, the $\mathrm{Cu}$-La master alloys were added into the copper melt covered with charcoal and graphite flake. The La content in the master alloys was approximately $15 \mathrm{wt} . \%$. The addition content of La in copper melt was $180 \mathrm{ppm}$. The TP2 copper tube billet was drawn after the temperature of the melt reached $1,150{ }^{\circ} \mathrm{C}$ and held for 1 hour. The withdrawing speed of samples No.1 and 3 was 378 $\mathrm{mm} \bullet \mathrm{min}^{-1}$, while that of sample No. 2 was $336 \mathrm{~mm} \bullet \mathrm{min}^{-1}$.

The chemical compositions of the specimens were determined using a SPECTRO OES unit, and the La content in the TP2 copper tube was measured by an Optima 7300 DV ICP-OES. The specimens were tested at $22{ }^{\circ} \mathrm{C}$ and $50 \%$ humidity. The chemical compositions of the HCC TP2 copper tube billets are shown in Table 1.

Table 1: Chemical compositions of HCC TP2 copper tubes (ppm)

\begin{tabular}{rcccccccccccc} 
No. & $\mathrm{Cu}(\%)$ & $\mathbf{P}$ & As & $\mathrm{Fe}$ & $\mathrm{Pb}$ & $\mathrm{Zn}$ & $\mathbf{S}$ & $\mathbf{0}$ & $\mathrm{Si}$ & $\mathrm{Ag}$ & $\mathrm{La}$ \\
\hline 1 & 99.977 & 182.7 & 5.0 & 19.7 & 1.0 & 5.5 & 4.4 & 58 & 1.0 & 6.3 & 0 \\
2 & 99.975 & 197.7 & 5.0 & 19.5 & 1.0 & 5.4 & 1.0 & 13 & 1.0 & 6.3 & 27 \\
3 & 99.975 & 197.1 & 5.0 & 19.6 & 1.0 & 5.3 & 1.0 & 11 & 1.0 & 6.3 & 30
\end{tabular}

The specimens cut from the HCC TP2 copper tube billets were polished with a series of abrasive papers and etched by $4 \% \mathrm{HNO}_{3}$ and $5 \% \mathrm{FeCl}_{3}+5 \% \mathrm{HCl}+90 \% \mathrm{C}_{2} \mathrm{H}_{5} \mathrm{OH}$ solution before metallographic observation. The microstructures were observed by a ZMEF4A OM and a SSX-550 SEM equipped with EDS in secondary electron mode operated at $15 \mathrm{kV}$. The compositions of phases were examined by EDS. The grain sizes were measured by intercept method using an image-pro plus software. Tensile tests were performed on an INSTRON 5582 electronic universal testing machine at ambient temperature with a tensile rate of about $1 \mathrm{~mm} \bullet \mathrm{min}^{-1}$ according to GB/T 228.1-2010 using rod sample and sheet sample. The samples are schematically shown in Fig. 1. The fractography characteristics were examined by SEM.

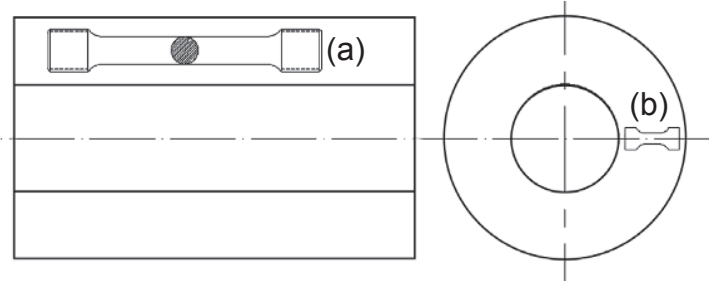

Fig. 1: Diagram of tensile test sample: (a) rod sample at axial direction, (b) sheet sample at transverse direction
The corrosion behavior in $0.5 \mathrm{~mol} \cdot \mathrm{L}^{-1} \mathrm{HCl}$ solution at room temperature of the TP2 copper tube with La microalloying was evaluated using a CS300 electrochemical workstation. The working electrode, reference electrode and counter electrode were the sample, a saturated calomel electrode (SCE) and a platinum electrode, respectively, in a standard three-electrode cell. In the present research, all the potentials were referred to SCE. The samples were mounted with an exposed area of 100 $\mathrm{mm}^{2}$ using epoxy resins, and were polished to mirror-like finish before the corrosion test. The potentiodynamic polarization tests were performed at a scan rate of $0.3 \mathrm{mV} \cdot \mathrm{s}^{-1}$. In order to ensure the accuracy of the results, all electrochemical measurements were repeated three times.

\section{Results and discussion}

\subsection{Absorptivity of La in TP2 copper tube}

Table 2 shows the addition and absorptivity of La in HCC TP2 copper tube. Due to the active chemical properties of $\mathrm{La}$, it is easy to react with other elements in copper and form clinkers, which led to the loss of La when La is added to the molten copper. Chen et al. ${ }^{[27]}$ reported that the limited absorptivity of $\mathrm{La}$ in copper under vacuum conditions was 
Table 2: Absorptivity of La in TP2 copper tubes under antivacuum condition

\begin{tabular}{ccccc} 
No. & $\begin{array}{c}\text { Addition } \\
(\mathbf{p p m})\end{array}$ & $\begin{array}{c}\text { Practical } \\
\text { content } \\
(\mathrm{ppm})\end{array}$ & $\begin{array}{c}\text { Burning } \\
\text { loss (\%) }\end{array}$ & $\begin{array}{c}\text { Absorptivity } \\
(\%)\end{array}$ \\
\hline 1 & 0 & 0 & - & - \\
2 & 180 & 27 & 85 & 15 \\
3 & 180 & 30 & 83.3 & 16.7
\end{tabular}

93\%. The burning loss of La under antivacuum conditions is obviously higher than that under vacuum conditions. The burning mechanism under antivacuum conditions is similar to that under vacuum conditions. Furthermore, there are some impurity elements in the copper melt, such as $\mathrm{O}, \mathrm{H}, \mathrm{S}, \mathrm{Pb}, \mathrm{Bi}$ and $\mathrm{Fe}$, and when $\mathrm{La}$ is added into the molten bath, it easily reacts with the impurities to form some compounds with high melting points and then be removed as slag. On the other hand, it is unavoidable that La reacts with oxygen in the air to form lanthanum oxide because of its high chemical activities. RE oxide with a high melting point and lower density is also removed to dross. Consequently, the remaining content of $\mathrm{La}$ in the HCC TP2 copper tube reduces greatly compared to its addition amount under antivacuum conditions.

Figure 2 and Table 3 show the EDS analysis results of casting dross. It can be seen that the casting dross contains $\mathrm{O}, \mathrm{P}$, $\mathrm{S}, \mathrm{Cl}, \mathrm{Cu}, \mathrm{La}$ and other elements, which demonstrated that $\mathrm{La}$ deprives $\mathrm{O}, \mathrm{P}, \mathrm{S}, \mathrm{Cl}$ and other impurities from the copper melt. The La, which influences the composition of the TP2 copper tube, has played a role in purifying the copper melt.

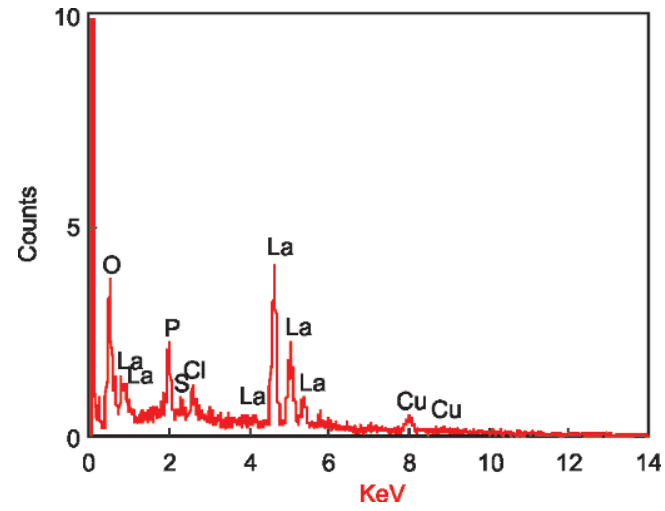

Fig. 2: EDS analysis of casting dross
Table 3: EDS analysis of casting dross

\begin{tabular}{ccc} 
Element & mass $\%$ & at. $\%$ \\
\hline $\mathrm{P}$ & 23.701 & 63.721 \\
$\mathrm{~S}$ & 5.942 & 8.252 \\
$\mathrm{Cl}$ & 1.342 & 1.801 \\
$\mathrm{Cu}$ & 2.502 & 3.036 \\
La & 7.065 & 4.782 \\
Total & 59.448 & 18.408 \\
\end{tabular}

\subsection{Microstructure}

Figure 3 displays the solidification structures of HCC TP2 copper tubes with and without La addition. It can be seen that, whether or not the La was added, there is inhomogeneous dendritic distribution along the circumferential direction, i.e., the columnar dendrite on the bottom of the tube billet is coarser than that on the upper side of the tube. The slight difference between the upper side and the bottom of the tube billet is normal in the horizontal continuous casting. This is due to the non-uniform heat dissipation between the upper side and the bottom of the tube billets during the horizontal continuous casting ${ }^{[28]}$. However, as shown in Fig. 4 and Fig. 5, the microstructure of HCC TP2 copper tubes with La addition was refined significantly. After La addition, the average columnar dendrite spacing was reduced to $0.93 \mathrm{~mm}$ with a reduction of approximately $57 \%$ compared with the average columnar dendrite spacing of $2.21 \mathrm{~mm}$ of the copper tube without $\mathrm{La}$ addition. The refinement mechanism can be described as follows: according to the metal solidification theory, when La was added to the molten copper, La element would be enriched at the front of the solid-liquid interface during the solidification process because of its lower melting point. Consequently, the constitutional undercooling degree at the front of the solid-liquid interface and the driving force of nucleation were increased during the solidification ${ }^{[29]}$. Thus, the nucleation velocity was enhanced, and the grains were refined. On the other hand, La element easily reacted with some impurity elements in copper, such as $\mathrm{O}$ and $\mathrm{S}$, to form oxide compounds, such as $\mathrm{La}_{2} \mathrm{O}_{3}, \mathrm{La}_{2} \mathrm{O}_{2} \mathrm{~S}$ and $\mathrm{La}_{2} \mathrm{~S}_{3}$. According to Ref. ${ }^{[30,31]}$, the melting points of $\mathrm{La}_{2} \mathrm{O}_{3}, \mathrm{La}_{2} \mathrm{O}_{2} \mathrm{~S}$ and $\mathrm{La}_{2} \mathrm{~S}_{3}$ are $2,249{ }^{\circ} \mathrm{C}, 1,940{ }^{\circ} \mathrm{C}$ and

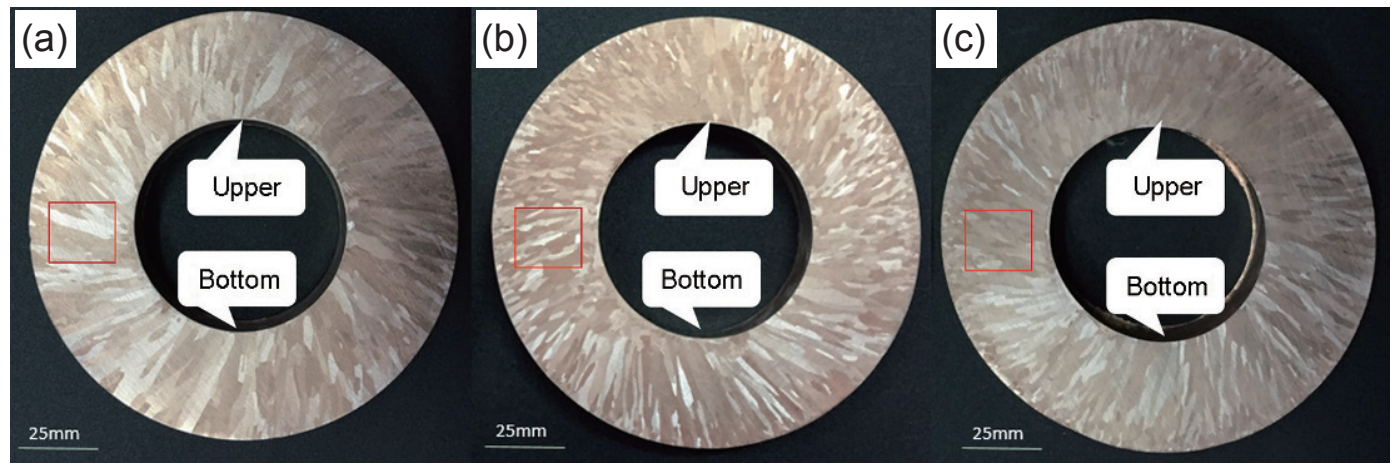

Fig. 3: Solidification structures of TP2 copper tube with and without La addition: (a) 0 La, (b) 27 ppm La, (c) 30 ppm La 

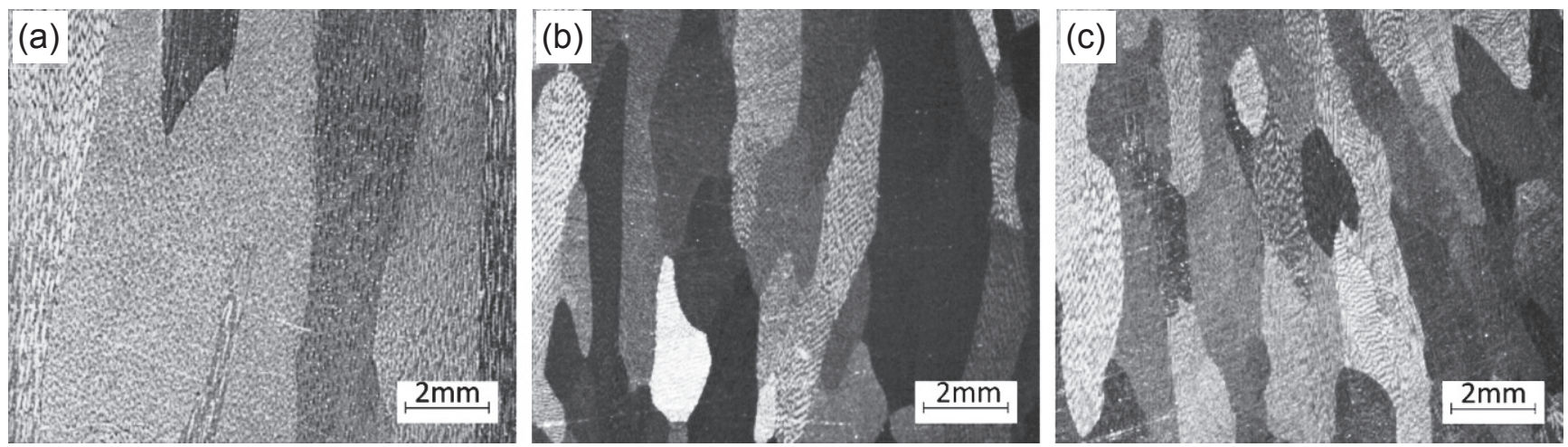

Fig. 4: Microstructures of TP2 copper tubes with and without La addition: (a) 0 La, (b) 27ppm La, (c) 30ppm La

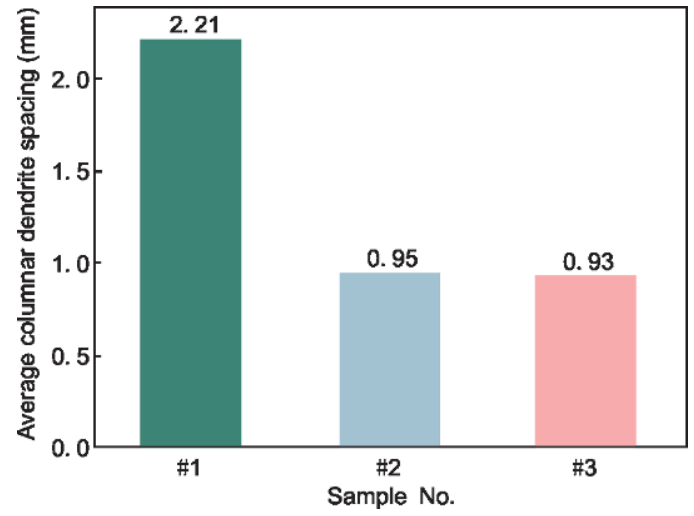

Fig. 5: Average columnar dendrite spacing of TP2 copper tube with and without La addition: \#1 0 La, \#2 27 ppm La, \#3 30 ppm La

2,099 ${ }^{\circ} \mathrm{C}$, respectively. Thus, these compounds would solidify much earlier than copper during the solidification process. Because of that, these precipitated phases can provide enough nucleating sites, and the growth of the columnar grains is impeded. As a result, the grains of the HCC TP2 copper tube with $\mathrm{La}$ addition were refined.

\subsection{Tensile properties}

Table 4 shows the ultimate tensile strength and elongation of HCC TP2 copper tubes with and without La addition. It can be seen that the ultimate tensile strength in the axial direction is almost at the same level as that in the transverse direction; while the elongation in transverse direction is much higher than that in the axial direction because the tensile direction is consistent with the dendrite growth direction. It can also be seen from Table 4 that the ultimate tensile strength and the elongation in axial direction are almost kept at the same levels with or without La addition, while, they are slightly improved in transverse direction. Figure 6 gives the SEM fractographs of tensile samples of the TP2 copper tube before and after La addition. It is obvious that some dimples distribute in the fracture surfaces of all samples, indicating the microscopic characteristics of ductile fracture. Therefore, combined with results in Table 4, it can be concluded that trace La has a small effect on the ultimate tensile strength and the elongation of HCC TP2 copper tube.

Table 4: Results of tensile tests

\begin{tabular}{|c|c|c|c|c|}
\hline \multirow{2}{*}{ Sample No. } & \multicolumn{2}{|c|}{ Axial direction } & \multicolumn{2}{|c|}{ Transverse direction } \\
\hline & Tensile strength (MPa) & Elongation (\%) & Tensile strength (MPa) & Elongation (\%) \\
\hline 1 & $160( \pm 1.2)$ & $40.5( \pm 0.5)$ & $141( \pm 1.1)$ & $85.8( \pm 0.5)$ \\
\hline 2 & $171( \pm 0.2)$ & $40.3( \pm 1.2)$ & $166( \pm 1.6)$ & $84.9( \pm 1.0)$ \\
\hline 3 & $167( \pm 1.5)$ & $40.5( \pm 0.8)$ & $158( \pm 1.0)$ & $90.8( \pm 1.2)$ \\
\hline
\end{tabular}
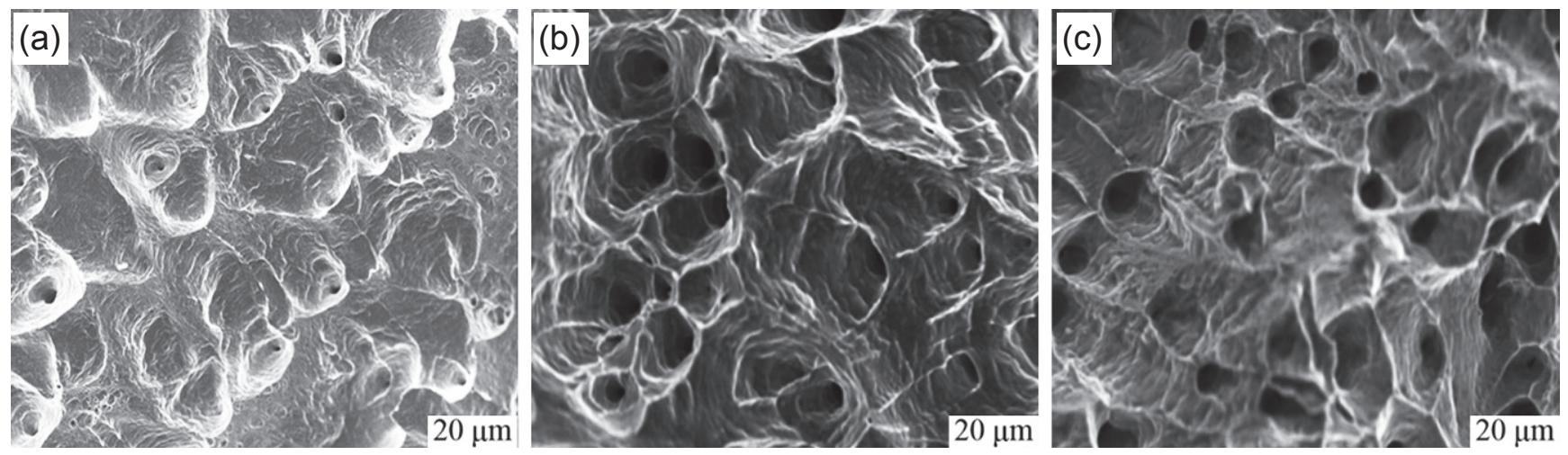

Fig. 6: SEM fractographs of tensile samples of TP2 copper tubes: (a) 0 La, (b) 27ppm La, (c) 30ppm La 


\subsection{Corrosion properties}

Figure 7 shows the potentiodynamic polarization curves of $\mathrm{HCC}$ TP2 copper tubes before and after La addition in $0.5 \mathrm{~mol} \cdot \mathrm{L}^{-1} \mathrm{HCl}$ solution at $25{ }^{\circ} \mathrm{C}$. Table 5 lists the electrochemical parameters obtained from the potentiodynamic polarization curves. Annual corrosion rate $V_{\mathrm{A}}$ can be calculated by Eq. (1):

$$
V_{\mathrm{A}}=\frac{3.16 \times 10^{8} I_{\mathrm{corr}} M}{z F \rho}
$$

where, $I_{\text {corr }}$ is corrosion current density, $M$ is metal molar mass $\left(\mathrm{g} \cdot \mathrm{mol}^{-1}\right), z$ is electron transfer number of a single metal atom,

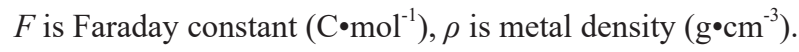

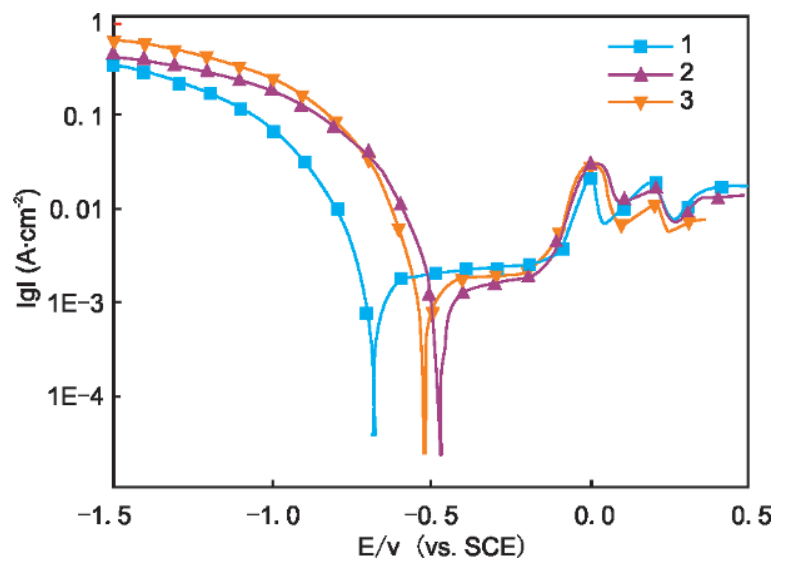

Fig. 7: Potentiodynamic polarization curves of different TP2 copper tubes in $0.5 \mathrm{~mol} \cdot \mathrm{L}^{-1} \mathrm{HCl}$ solution at $25^{\circ} \mathrm{C}$

From Fig. 7 and Table 5, it can be seen that the corrosion potential $E_{\text {corr }}$ of the HCC TP2 copper tube with La addition is higher than that without La addition, while the corrosion current density $I_{\text {corr }}$ and annual corrosion rate $V_{\mathrm{A}}$ of the $\mathrm{HCC}$ TP2 copper tube with La addition are lower than that without La addition. After La addition, the cathodic polarization curve of HCC TP2 copper tubes moves to the positive direction, the corrosion potential of copper tubes increases from $-679.31 \mathrm{mV}$ to $-471.91 \mathrm{mV}$ and $-521.67 \mathrm{mV}$, respectively; and at the same time, the corrosion current density significantly decreases from $432.2 \mu \mathrm{A} \cdot \mathrm{cm}^{-2}$ to $398.04 \mu \mathrm{A} \cdot \mathrm{cm}^{-2}$ and $417.64 \mu \mathrm{A} \cdot \mathrm{cm}^{-2}$, and the annual corrosion rate decreases from 10.18 to 9.84 and $9.37 \mathrm{~mm} \cdot \mathrm{a}^{-1}$ correspondingly, suggesting that the corrosion resistance of HCC TP2 copper tubes is improved by virtue of La addition.

The higher the corrosion potential $E_{\text {corr }}$, the more difficult the electronic loss becomes, and the better the corrosion

Table 5: Electrochemical parameters obtained from potentiodynamic polarization curves of different TP2 copper tubes

\begin{tabular}{|cccc|}
\hline Sample No. & $\mathbf{1}$ & $\mathbf{2}$ & $\mathbf{3}$ \\
\hline$E_{\text {corr }}{ }^{*}(\mathrm{mV})$ & -679.31 & -471.91 & -521.67 \\
$I_{\text {corr }}\left(\mu \mathrm{A} \cdot \mathrm{cm}^{-2}\right)$ & 432.2 & 417.64 & 398.04 \\
$V_{\mathrm{A}}\left(\mathrm{mm} \cdot \mathrm{a}^{-1}\right)$ & 10.18 & 9.84 & 9.37 \\
\hline
\end{tabular}

${ }^{*}: E_{\text {corr }}$ is corrosion potential resistance of a material in thermodynamics. The lower the corrosion current density, the better the corrosion resistance of a material ${ }^{[32]}$. Figure 7 shows that the shapes of the polarization curves before and after La addition are similar, indicating that the corrosion mechanisms are the same. The corrosion mechanisms are all controlled by cathode reactions, while the effect of electrochemical corrosion mechanism is weak. There are some impure elements in copper, such as $\mathrm{O}, \mathrm{H}, \mathrm{S}, \mathrm{Pb}, \mathrm{Bi}$, and Fe. The impurity elements can form compounds or eutectic with copper, which have a potential higher than that of copper. The compounds or eutectic can act as cathode in the corrosive medium and copper acts as anode, so the existence of impure elements in copper promotes the electrochemical corrosion of copper. Due to its active chemical properties, La can react with the harmful impurity elements in copper. Therefore, the impurities can be removed by La addition. The areas of cathode were reduced, and then the cathode reaction was restrained, lowering the corrosion speed of anode copper. The galvanic corrosion was weakened and the corrosion resistance of HCC TP2 copper tubes was improved. As shown in Table 1 , the content of impurity elements $(\mathrm{O}, \mathrm{S}$, et al) in copper are decreased, hence, the corrosion resistance of TP2 copper tube becomes better.

\section{Conclusions}

The effects of trace La microalloying on microstructures, mechanical and corrosion properties of HCC TP2 copper tubes were investigated. The following conclusions can be drawn based on the results of the experiment:

(1) The absorptivity of La in HCC TP2 copper tube in the actual production conditions is about $15 \%$, which is much lower than that under vacuum conditions.

(2) The average columnar dendrite spacing of the HCC TP2 copper tube with La addition are refined obviously from 2.21 $\mathrm{mm}$ to $0.93 \mathrm{~mm}$.

(3) Trace La has a small effect on the ultimate tensile strength and the elongation of HCC TP2 copper tubes. However, the annual corrosion rate decreases from $10.18 \mathrm{~mm} \cdot \mathrm{a}^{-1}$ to $9.37 \mathrm{~mm} \cdot \mathrm{a}^{-1}$, so the corrosion resistance of the HCC TP2 copper tubes in $\mathrm{HCl}$ solution is improved by the purifying effect of $\mathrm{La}$.

\section{References}

[1] Lu Lei, Shen Yongfeng, Chen Xianhua, et al. Ultrahigh strength and high electrical conductivity in copper. Science, 2004, 304(5669): 422.

[2] Popovich A, Sufiiarov V, Polozov I, et al. Microstructure and mechanical properties of additive manufactured copper alloy. Materials Letters, 2016, 179: 38-41.

[3] Peltola $\mathrm{H}$, Lindgren $\mathrm{M}$. Failure analysis of a copper tube in a finned heat exchanger. Engineering Failure Analysis, 2015, 51: 83-97.

[4] Pan Zhenya, Chen Jiangbiao, Li Jinfu. Microstructure and properties of rare earth-containing $\mathrm{Cu}-\mathrm{Cr}-\mathrm{Zr}$ alloy. Transactions of Nonferrous Metals Society of China, 2015, 25(4):1206-1214.

[5] Kamyshanchenko N V, Durykhin M I, Gal'tsev A V, et al. Effect 
of microalloying of copper with yttrium on its structure and mechanical properties. Inorganic Materials, 2011,47(14):15921595.

[6] Ding Jiayuan, Huang Shaohui, Chao Guohui, et al. A high strength and corrosion resistance of micro-alloyed brass and its manufacturing method. China patent: 103866157 A, 2014-0618. (In Chinese)

[7] Cai Guojun, Li Changsheng. Effects of Ce on inclusions, microstructure, mechanical properties, and corrosion behavior of AISI 202 stainless steel. Journal of Materials Engineering and Performance, 2015, 24(10): 3989-4009.

[8] Gao Zhaohe, Li Hongying, Lai Yongqiu, et al. Effects of minor $\mathrm{Zr}$ and $\mathrm{Er}$ on microstructure and mechanical properties of pure aluminum. Materials Science and Engineering A, 2013, 580(10): 92-98.

[9] Serge G, Mark A E, Mark A G, et al. Microstructure and property evaluation of high-pressure die-cast Mg-La-rare earth ( $\mathrm{Nd}, \mathrm{Y}$ or Gd) alloys. Journal of Alloys and Compounds, 2014, 597(11): 21-29.

[10] Chen Zhongwei, Tang Mingjun, Zhao Kai. Effect of rare earth samarium addition on the kinetics of precipitation in Al-Cu-Mn casting alloy. International Journal of Minerals, Metallurgy and Materials, 2014, 21(2): 155-161.

[11] Ning Yuantao, Zhang Xiaohui, Qin Guoyi. Influence of cerium addition on microstructure and properties of $\mathrm{Cu}-\mathrm{Ag}$ alloy in situ filamentary composites. Journal of Rare Earths, 2005, 23(s1): 392-398.

[12] Li Haihong, Sun Xueqin, Zhang Shangzhou, et al. Application of rare-earth element $Y$ in refining impure copper. International Journal of Minerals, Metallurgy and Materials, 2015, 22(5): 453459.

[13] Liu Jiabin, Meng Liang, Zhang Luona. Rare earth microalloying in as-cast and homogenized alloys $\mathrm{Cu}-6 \mathrm{wt}$ \% $\mathrm{Ag}$ and $\mathrm{Cu}-$ 24wt.\%Ag. Journal of Alloys and Compounds, 2006, 425(1): 185-190.

[14] Li Haihong, Zhang Shihong, Chen Yan, et al. Effects of Small Amount Addition of Rare Earth Ce on Microstructure and Properties of Cast Pure Copper. Journal of Materials Engineering and Performance, 2015, 24(8): 2857-2865.

[15] Li Ming, Hao Hai, Zhang Ai-min, et al. Effects of $\mathrm{Nd}$ on microstructure and mechanical properties of as-cast Mg-8Li-3AI alloy. Journal of Rare Earths, 2012, 30(5): 492-496.

[16] Zhang Zhenfeng, Lin Gaoyong, Zhang Shenghua, et al. Effects of $\mathrm{Ce}$ on microstructure and mechanical properties of pure copper. Materials Science and Engineering: A, 2007, 457(1): 313-318.

[17] Chen Yan, Cheng Ming, Song Hongwu, et al. Effects of lanthanum addition on microstructure and mechanical properties of as-cast pure copper. Journal of Rare Earths, 2014, 32(11):1056-1063.
[18] Zhang Liang, Xue Songbai, Gao Li-li, et al. Effects of trace amount addition of rare earth on properties and microstructure of $\mathrm{Sn}-\mathrm{Ag}-\mathrm{Cu}$ alloys. Journal of Materials Science: Materials in Electronics, 2009, 20(12): 1193-1199.

[19] Liu Jiabin, Zeng Yuewu, Meng Liang. Crystal structure and morphology of a rare-earth compound in Cu-12wt.\% Ag. Journal of Alloys and Compounds, 2009, 468(1): 73-76.

[20] Hu Zhi, Yan Hong, Rao Yuansheng. Effects of samarium addition on microstructure and mechanical properties of as-cast Al-Si-Cu alloy. Transactions of Nonferrous Metals Society of China, 2013, 23(11): 3228-3234.

[21] Liu Guanglei, Si Naichao, Sun Shaochun, et al. Effects of grain refining and modification on mechanical properties and microstructures of Al-7.5Si-4Cu cast alloy. Transactions of Nonferrous Metals Society of China, 2013, 312(24): 946-953.

[22] Mao Xiangyang, Fang Feng, Jiang Jianqing, et al. Effect of rare earth on the microstructure and mechanical properties of ascast Cu-30Ni alloy. Rare Metals, 2009, 28(6): 590-594.

[23] Wu Zhiwei, Chen Yi, Meng Liang. Effects of rare earth elements on annealing characteristics of $\mathrm{Cu}-6 \mathrm{wt} . \% \mathrm{Fe}$ composites. Journal of Alloys and Compounds, 2009, 477(1): 198-204.

[24] Rosalbino F, Carlini R, Soggia F, et al. Influence of rare earth metals addition on the corrosion behaviour of copper in alkaline environment. Corrosion Science, 2012, 58(5): 139-144.

[25] Chen Jinglin, Li Zhou, Zhu Anyin. Corrosion behavior of novel imitation-gold copper alloy with rare earth in $3.5 \% \mathrm{NaCl}$ solution. Material and Design, 2012, 34:v618-623.

[26] Lin Gaoyong, Zhou Yuxiong, Zeng Juhua, et al. Influence of rare earth elements on corrosion behavior of Al-brass in marine water. Journal of Rare Earths, 2011, 29(7): 638-644.

[27] Chen Yan, Zhang Shihong, Song Hongwu, et al. Sudden transition from columnar to equiaxed grain of cast copper induced by rare earth microalloying. Material and Design, 2016, 91(s1): 314-320.

[28] Li Xintao, Guo Zhangxiang, Zhao Xiangwei, et al. Continuous casting of copper tube billets under rotating electromagnetic field. Materials Science and Engineering A, 2007, 460-461: 648-651.

[29] Zhang Yu, Huang Xiaofeng, Ma Ying, et al. Effects of Sm addition on microstructural evolution of $\mathrm{Mg}-6 \mathrm{Zn}-0.4 \mathrm{Zr}$ alloy during semi-solid isothermal heat treatment. China Foundry 2017, 14(2): 85-92.

[30] Waubdy P E. Rare earth addition to steel. International Materials Reviews, 1978, 23(1): 74-99.

[31] Wang Zhiwen, Wang Hongxia, Gong Jialin, et al. Modification and refinement effects of $\mathrm{Sb}$ and $\mathrm{Sr}$ on Mg17Al12 and Mg2Si phases in Mg-12Al-0.7Si alloy. China Foundry, 2016, 13(5):310315.

[32] Chen Zhongwei, Chen Pei, Ma Cuiying. Microstructures and mechanical properties of Al-Cu-Mn alloy with La and Sm addition. Rare Metals, 2012, 31(4): 332-335.

This work was financially supported by the Plan of the Chinese Academy of Sciences (CAS) to Provide Science \& Technology (S\&T) Support and Service for National Strategic Emerging Industries (Grant No.: 2012037), and the Science Foundation of the Chinese Academy of Sciences (Grant No.: 2012005). 